\title{
A Research of College English Reflective Teaching in China*
}

\author{
Junqiu $\mathrm{Wu}$ \\ Foreign Language Department, Huaiyin Institute of Technology, 223003, Jiangsu, China \\ Yongpeng $\mathrm{Wu}$ \\ College of Physical Science, South China Normal University, 511400, Guangzhou, Guangdong, China
}

\begin{abstract}
Reflective teaching", as a reform in international teachers' education as well as a theory of teacher training, aims to promote teachers professional development. Based on the analyses of moral responsibility of teaching and actual result of teaching techniques, it has gradually developed into a powerful teaching trend which has been influencing practice of education all over the world. This paper aims to clarify the following problems: what is reflective teaching; why is reflective teaching worth doing. By analyzing the theoretical bases and previous research of reflective teaching, it further proposed five aspects of reflective teaching for high school teachers to employ in their teaching practice in China.
\end{abstract}

Index Terms — reflective teaching, English teaching, practice

\section{INTRODUCTION}

The general and long standing problem of China's college English education is that much time is consumed but little effect achieved. The inefficient and even negative classroom teaching can't meet the needs of the fast development of China, nor to suit the needs of opening up to the outside world. Who are the most to blame, educational system, teachers or learners? Some people may say under the current educational system centered on National College Entrance Exams, both teachers and learners are test-driven and busy with all kinds of tests. However, some experts are convinced that it is the teachers who should take the larger part of the blame for the low efficient learning. Most college teachers are experience-oriented and have simply been teaching on empirical basis. Such simple and empirical teaching for twenty years may be just a repetition of twenty times for a year's work. Empirical teaching is known as the one that copies mechanically and applies indiscriminately learning theories or lack of analysis and reasoning. Those who adopt traditional teaching method are called experience-oriented teachers. Most empirical teachers practice automatically and intuitively and rely on the description of the theories which are beyond their understanding. In addition, they make interactive decisions on the basis of instinct and intuition rather than reflection and rationale. On the contrary, effective teaching is characterized by making decisions through reflection, rationale and consciousness. Therefore it is necessary for us to seek inspiration in which teachers may reflect what they are doing and why they are doing it.

Since reflective teaching theory was first introduced to China in the 1990s, it has aroused much concern in the field of teaching theory and practice. Reflective teaching, in brief, is one in which all the teaching process is reflected so as to be improved constantly, and it is also a process in which teachers criticize and analyze their teaching by virtue of logical reasoning, scrutiny, judgment and the positive attitude toward reflection. The reason why reflective teaching springs up lies in the fact that reflective teaching, in nature is to inspire the teachers to reflect on their teaching style and thus find their problems and shortcomings for further improvement. The more teachers reflect, to some extent, the better they will teach and the better the teaching outcomes will be. Therefore, it is necessary to encourage teachers to adopt reflective teaching.

To adopt reflective teaching, on the one hand, is in the hope of consistently finding problems by examining one's teaching practice. On the other hand, it will further arouse teachers' sense of responsibility and awareness to improve their teaching. Traditional teaching practice focuses on what to teach and how to teach on the part of the teacher, but it ignores how to learn on the part of learners. Besides, it lays stress on imparting knowledge while paying little attention to language practice and usage. Such teaching not only frustrates learner's enthusiasm of language learning, but also throttles students and teachers' creativity. Consequently, it has vital theoretical and practical significance to probe into the nature and implication of reflective teaching in college English instruction.

\section{SIGNIFICANCE OF THE STUDY}

Reflective teaching aims to bridge the gap between theory and practice. Theory and practice are two integrate parts in qualified education as well as teachers' professional development. Theory serves as a guide and direction for the

\footnotetext{
${ }^{*}$ This paper is subsidized by the teaching reform projects of Huaiyin Institute of Technology, JYC201319
} 
teachers while practice takes a domain role in shaping teacher development. In education, the problem of how to bridge theory with practice becomes a severe question which has haunted educators for decades. All studies on teacher development emphasize that it is very difficult for an individual to influence established patterns in schools. Educational change seems to be a beautiful idea of teacher educators, but generally not much more than an ideal. The teacher education is faced with a severe problem that is it creates little transfer from theory to practice. Elliot (1991, p.45) points out that 'teachers often feel threatened by theory' and these feelings are further strengthened by the society. The reality is that though teachers are aware of the importance of theory as a means to support practice, the everyday problems in their classrooms which they are struggling with leaves the idea of applying theory an impossible mission. It follows then the teachers choose to consider teacher education too theoretical and useless in order to get out of the sense of frustration. While this turned out to only widen the gap between theory and practice. Elliot (1991, p.47) concludes:

The perceived gap between theory and practice originates not so much from demonstrable mismatches between ideal and practice but from the experience of being held accountable for them.

Reflective teaching offers an alternative approach and is given a central place in teacher education. Reflection is considered to be an important means to link theory and practice for it helps teachers to become teacher researchers through critical reflection about their teaching behaviors. The strength of teacher researcher is the development of a better understanding of classroom practice in ways that are specific and local. What experts lack is a teacher's insider perspective on the classroom context and the research findings they generalized are to the larger educational community. To become a teacher researcher means that the teacher can thoughtfully examine and analyze classroom practices through intentional and systematic inquiry into teaching. Calderhead and Gates (1993, p.2) maintain that teacher education programs based on notions of reflective practice espouse one or more of the following aims:

1. To enable teachers to analyze, discuss, evaluate and change their own practice, adopting an analytical approach towards teaching;

2. To foster teachers' appreciation of the social and political contexts in which they work, helping teachers to recognize that teaching is socially and politically situated and that the teacher's task involves an appreciation and analysis of that context;

3. To enable teachers to appraise to moral and ethical issues implicit in classroom practice, including the critical examination of their own beliefs about good teaching;

4. To encourage teachers to take greater responsibility for their own professional growth and to acquire some degree of professional autonomy;

\section{TheORETICAL BASES OF REFLECTIVE TEACHING}

Reflective teaching is base on principles of well-debated schools of thought, and by its very 'intentional' nature is bound up in phenomenological discourses. It is connected to theories of cognition and meta-cognition, constructivism and humanism.

\section{A. Definition}

About reflective teaching there is no single or simple definition. It is hard to place a definitive label on it because of the complexity of the action itself. Reflective teaching is derived from a philosophy idea --- reflection, which was first put forward by Dewey in 1930's in his works How We Think. Dewey(1933,p.4) defines reflection as that 'it involves not simply a sequence of ideas, but a consequence---a consecutive ordering in such a way that each idea determines the next as its proper outcome, while each outcome in turn learns back on, or refers to, its predecessors'.

This concept of Dewey is extended by Schon. His (Schon, 1988) contribution is to combine reflection with teachers' professional development and divided reflection into 'reflection-in-action' and 'reflection-on-action'.

The popularization of reflective teaching is due to the contribution of Cruickshank and Applegate (Cruickshank et al, 1981) and Zeichner (Zeichner, 1981,p.2). They have reported on projects attempting to assist both pre-service and experienced teachers to teach 'reflectively'.

Critical reflective teaching involves conscious recall and examination of a past experience as a basis for evaluation and decision-making and as a source for planning and action. The critical reflection process starts with the lesson itself or any other teaching activities. After the lesson or teaching activities is the analytical evaluation----the process of critical reflection. Osterman \& Kottkamp (2004,p.26) claim that 'the process develops in an experiential learning cycle where a problematic experience is crucial to other ranked stages in the cycle----problem identification, observation and analysis, abstract re-conceptualization and active experimentation'. Pollard (2005) holds a similar perspective by illustrating that the reflective process is manifested in a cyclical manner, which Pollard illustrates this way: 


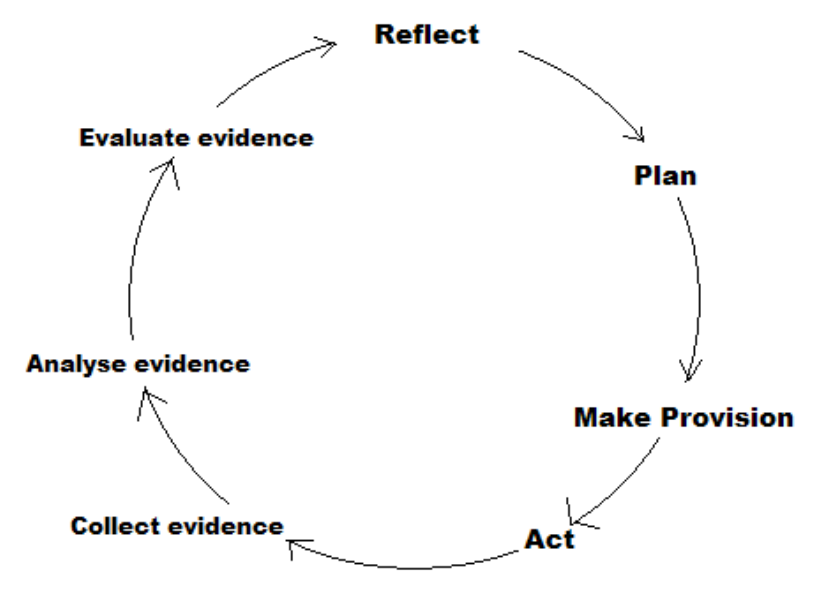

Figure 1: The Process of Reflective Teaching (Pollard, 2005,p.17)

This reflective process and action are closely related to teacher motivation, teacher competency, professional attitude, referring to Dewey's analogy, 'the teacher as a lover'. This seemingly weird idea can be interpreted in the context of 'a lover of learning, knowledge, any subject area, interacting with learners, imparting knowledge and stimulating intellectual curiosity, among others'(Simpson, et al, 2005,p.29). Cohn and Kottkamp (1993, p.228) interpret it from an alternative context by analyzing teachers' perception of good teaching and learning. Teachers are supposed to understand learners' reality, to feel what the student feels, and to act in the students' interest. These issues certainly help to establish the complexities involved in the reflective teaching process.

It is obvious that there are many conceptions about reflective teaching and its related practices. Besides, both the researchers and the practitioners agree that the purpose for the idea of continuous and repeated action lies in improving professional practice and engaging the students in meaningful and productive activities. But all teacher actions should be based on qualified teacher education and training principles, which include knowledge of the theoretical structure that frames instructional activities. Reflective teaching is no exception.

\section{B. Cognition and Meta-cognition}

Cognition refers to "the act or process of knowing in the broadest sense; specifically, an intellectual process by which knowledge is gained from perception or ideas"(Webster's Ninth New Collegiate Dictionary 1999). As a teaching method cognitive apprenticeship mainly focuses on dealing with tough problems in the process of teaching. The Collins-Brown model of cognitive apprenticeship contains several instructional principles, listed below: (Wilson \& Cole, 2000, p.47-64)

1. Content: Teach tacit, heuristic knowledge as well as textbook knowledge.

2. Situated learning: Teach knowledge and skills in contexts that reflect the way the knowledge will be useful in real life.

3. Modeling and explaining: Show how a process unfolds and tell reasons why it happens that way.

4. Coaching and feedback: Teachers should facilitate the students completing their tasks by providing instructions and helps when necessary.

5. Scaffolding and fading. Support learners by performing parts of the task they cannot perform.

6. Articulation and reflection: Have students think about and give reasons for their actions, thus making their tacit knowledge more explicit.

7. Exploration: Encourage students to try out different strategies and observe their effects.

8. Sequence: Proceed in an order from simple to complex, with increasing diversity. Increasing diversity means you explore the full domain of interest.

Meta-cognition is "thinking about thinking", knowing "what we know" and "what we do not know". Basic metacognitive strategies are self-appraisal and self-management of cognition. Self-appraisal refers to people's personal reflections about their cognitive ability and emotional states concerning their knowledge states, abilities, motivation and characteristics. Self-management is mental processes that help to mastermind aspects of problem solving.

\section{Constructivism Theory}

In education, the heart of constructivism is critical thinking. It is well established among researchers and theorists that critical thinking is a purposeful mental activity that employs problem-solving skills at all levels in the cognitive domain. This acknowledgement uncovers the importance of employing a constructivist approach in reflective teaching and learning activities. 
Different from a particular pedagogy, constructivism is a theory describing how learning happens, regardless of whatever the learners are using their experiences to do. It suggests that learners construct knowledge out of their experiences and it is often associated with pedagogic approaches that promote active learning, or learning by doing.

Vygotsky (1978) pays attention to social constructivism and regards it as the essential part in cognitive development. Saunders (1992) explains that "Constructivism can be defined as that philosophical position which holds that any socalled reality is, in the most immediate and concrete sense, the mental construction of those who believe they have discovered and investigated it." Steffe (1990) explains, "Constructivists view learning as the adaptations children make in their functioning schemes to neutralize perturbations that arise through interactions with our world." Wheatly (1991) suggests two principles of learning through the constructivist theory.

\section{Humanism Theory}

To be reflective is to be human. Thinking about oneself, other people and things happening in the world is a natural human reaction. It is universally acknowledged that an active, experiencing person is at the core of every human action. And reflection and self-reflection are an inevitable part of human activities, including the teaching and learning activities. Though important, it tends to be neglected by teachers to find a systematic formal approach to reflective practices in the classroom.

Humanistic teaching method is suitable for the quality-based teaching in China, but it remains a problem about what and how the teachers should do accordingly. According to Gage and Berliner (1991), some basic principles of the humanistic approach are used to develop the objectives:

1. Students will learn best what they want and need to know.

2. Self-evaluation is the only meaningful evaluation of a student's work with its emphasis on internal development and self-discipline.

3. Feelings are as important as facts. Educators are making significant contributions to our knowledge from the perspective of humanism.

4. Students learn best in a non-threatening environment.

\section{Previous Research of Reflective Teaching in China}

Since "reflective teaching" was introduced to China in the 1990s, a series of theoretical and practical research have been made on reflective teaching. While compared with the studies aboard, we still have a lot more to work on, especially on the relationship between teacher's professional development and reflective teaching. What's more, studies on reflective teaching in secondary school English classrooms in China emerged only in recent years.

Among the several kinds of monographs, only a few are written by Chinese people while most of them are translated versions. There is only one famous book on reflective teaching, which is written by Professor Xiong Chuanwu(1999) from East China Normal University. He defines reflective teaching as teachers continuously inquiring and solving the problems generated from inner self, teaching goals and teaching methods by means of action research, and by combing 'learning how to teach' with 'learning how to learn'. So teachers can make full play of the role of teaching practical rationality and finally become more experienced. Another book is reflective teaching edited by Jin(2006) , which includes a large number of cases analyses to put forward concrete implementation strategy and teaching practice of reflective teaching in accordance with the teaching practice in elementary education.

Wei (2005) takes teaching blog as subject, analyzing teachers' reflection state and their problems in order to promote teachers' reflective ability. Statistics show that most of teachers' reflection stays in the technical level and few on the teaching concepts and scientific research. His research also shows that problems of relatively abstract teaching concepts are more suitable for collective reflection. What Wei's study implies is that teachers can achieve a better understanding of teaching concepts through reflective teaching instead of through simple training or teacher education.

Currently in China, there are about 60 theses by graduate students concerning reflective teaching and nearly 600 published articles on reflective teaching, most of which are written by the researchers and teachers from the developed areas in China. Rare research about reflective teaching can be found in China's western region. This phenomenon reflects the imbalance of different regions in accepting or applying this teaching concept. What's more, people mainly study the mode of reflective teaching and basic theories instead of how to reflect by teachers themselves.

\section{Aspects of Reflective TeAching}

In the previous sections, the researcher has reviewed what reflective teaching is and why reflective teaching is worth doing literally. With its aim to bridge the gap between theory and practice, reflective teaching facilitates teachers to become teacher researchers to explore and solve the teaching problems by themselves. In this section, the researcher will focus on the aspects of reflective teaching and present suggestions for college English teachers to follow in their daily teaching practice.

\section{A. Reflection of Teachers' Beliefs}

Teachers' beliefs can be thought of as a belief substructure that interrelates with all other beliefs; they have a filtering effect on everything that teachers think about, say, and do in classrooms. 
The characteristics of teachers' beliefs are inextricably complex, grounded in emotional laden episodic memories from prior experiences, relatively stable and resistant to change, yet instrumental in shaping how teachers interpret what goes on in their classrooms and how they will respond to that. Teachers' beliefs have a powerful impact on the nature of a teachers' reasoning since the ways in which teachers come to conceptualize themselves as teachers and develop explanations for their own classroom practices tend to be filtered through their beliefs.

EFL teachers should reflect on the following aspects before setting out to teach:

1. Beliefs about English: English represents different things to different people.

In the case of English, there are significant differences between different individuals. Therefore it is helpful for us to check the following beliefs that teachers think about English. Teachers should consider the following questions:

Why do you think English is an important language?

What do you think are the most difficult aspects of learning English are (e.g., grammar, vocabulary, pronunciation)? What attitudes do you think your learners associate with English?

2. Beliefs about learning: teachers' beliefs about learning are based on their training and their teaching experience, especially their informal language learning experiences. Informal language learning experiences in which the language functions as a means of meaningful communication in real social situations can leave powerful imprints on teachers. Teachers should consider the following questions:

How do you define learning?

What are the best ways to learn a language?

What kind of learning styles and strategies do you encourage in learners?

What roles are students expected to take in your classroom?

3. Beliefs about teaching: It is inevitable for the teachers to bring their personal beliefs and ideas to teaching in order to achieve effective teaching. Teachers should reflect on the following questions:

How do you see your role in the classroom? How would this be apparent to a visitor?

What teaching methods do you try to implement in your classroom?

What is your approach to classroom management?

4. Beliefs about the program and the curriculum: Within a program or a school, teachers' views on such things as lesson planning, the use of objectives and assessment may lead to quite different classroom practices. Teachers should consider the following questions:

What do you think the role of textbook and teaching materials in a language program should be?

To what extent is your teaching based on your students' needs?

What changes would you like to see in your teaching?

5. Beliefs about language teaching as a profession: Professionalism is a recurring concern of language teachers and language teaching organizations (Pennington, 1991). The following questions further explore teachers' beliefs:

Do you regard English teaching as a profession?

What are the necessary changes in the language teaching profession?

What is the most rewarding aspect of teaching for you?

\section{B. Reflection on Teachers' Decision Making}

For many educationalists, decision making is viewed as an essential teaching competency. Shavelson (1973,p.143145) observed:

Any teaching act is the result of a decision, either conscious or unconscious... what distinguishes the exceptional teacher is not the ability to ask, say, a higher-order question, but the ability to decide when to ask such a question.

Teachers' decision making has been thought of as a process in which teachers consider a range of alternative instructional options and then choose, interactively, those which seem most appropriate. Richard \& Lockhart (1996) define three types of decisions: planning decisions, interactive decisions, and evaluative decisions.

1. Planning decisions: decisions made before a class.

Planning decisions are made after a process of reflection (Neely, 1986), during which the teacher has to consider questions such as:

Why should I teach this lesson?

What activities will be included in the lesson?

How will the lesson connect to what students already know?

How will I deal with different student ability levels in the class?

What role should I take on during the lesson?

2. Interactive decisions: classroom teaching is dynamic, unpredictable and full of changes. Thus teachers have to continuously make decisions to deal with the dynamics of the lesson. These kinds of decisions are called interactive decisions. Teachers should reflect on the following questions:

Do the students understand this? Are my instructions clear and understood?

Do I need to increase student involvement in this activity?

Should I try teaching this a different way?

How can I get the students' attention?

Am I teaching too much rather that letting the learners work it out for themselves? 
3. Evaluative decisions: decisions made by a teacher after a lesson has been taught. They arise from asking the following questions:

What were the main strengths and weaknesses of the lesson?

Did the lesson arouse students' interest in the subject matter?

Do I need to re-teach any part of the lesson?

What would be a suitable follow-up to the lesson?

Will I teach the material in the same way next time?

\section{Reflection of Teachers' Role}

Teachers' roles are determined by many factors such as their personalities, different schools they work in, and the different teaching methods they use as well as their particular culture backgrounds. It is these dimensions of teachers' roles that form the focus of reflective teaching.

1. Roles reflecting institutional factors; the different institutional administrative moulds different roles for teachers. In fact, teachers would like to take on more responsibilities, especially in the areas of needs identification, selecting and grading content, grouping learners, and course evaluation.

2. Roles reflecting teaching methods: different language teaching methods and approaches create specific roles for both teachers and learners. The teacher has two main roles: the first is to facilitate the communication process between all participants in the classroom, among these participants and the various activities and texts. The second role is to act as an independent participant within the learning-teaching group. The latter role is closely related to the objective of the first role and arises from it. (Breen \& Candlin, 1980, p.99)

3. Roles reflecting personalities: each teaching style is a unique one which teacher develops through their experience and adopt it in different ways according to the demands of specific situations.

4. Roles reflecting culture: The teaching profession is characterized by culture in which language represents the shaped perceptions, conceptions, and acceptable actions of its member. Thus, learning the language of practice is vital to learning to teach, since without knowledge of the language of practice, teachers cannot operate as full members of the culture of teaching.

\section{Reflection of Interaction in the English Classroom}

In language teaching, interaction is, in fact, the heart of communication; it is what communication is all about. In managing class interactions teachers need to guarantee that all students have equal opportunities to participate in. From this point of view, choosing an appropriate arrangement for specific learning activities becomes an important decision for EFL teachers. They should reflect on what ways should be used before interacting with the students in the class. The widely used arrangements are as follows:

1. Whole-class teaching: The teacher organizes the whole class with a learning task.

2. Individual work: each student in the class finishes some learning work by themselves without the help of teachers or other students.

3. Pair work: students work in pairs to complete a task.

4. Group work: students work in groups on learning tasks.

\section{CONCLUSION}

As Xiong (1999) states as a process of teachers development in all-around, reflective teaching emphasizes the combination of 'learning how to teach' with 'learning how to learn'. Though compared with 'learning how to learn', 'learning how to teach', a relative new concept, has something in common with 'learning how to learn' in that 'learning how to teach' actually is a kind of learning itself, for it requires teachers to take teaching as a process of learning, in which they learn not only teaching skills but ethics and moral knowledge. Such repetition of process of learning and practice will lead to teacher development, enable them to become teacher-researcher and elevate teaching eventually. Providing teachers with a further in-service education, reflective teaching probabilizes teachers' sustainable development that presupposes sustainable development of school. Reflective teaching is not only beneficial to teachers' current but also their life-long learning, which is just the goal of our education.

Although we have achieved a lot through this reflective practice, we still need to pay attention to many points concerning the theoretical study and practice of reflective teaching based on the current educational situation in China. These points include: First, reflective teaching is not a simple denial of the traditional teaching. Second, reflective activities should be conducted in various ways without limit in time or place. Third, teachers' reflective activities are restricted by subjective experiences and external factors, making it natural for them to make mistakes. Finally, the processing of teachers' reflective activities needs better working atmosphere and policy support.

\section{REFERENCES}

[1] Breen, M. \& Candlin.CN. (1980). The essentials of a communicative curriculum in language teaching. Applied Linguistics, vol. 1, no. 2, 89-112.

[2] Calderhead, J. \& Gates. P. (1993). Conceptualizing reflection in teacher development, London: Falmer Press. 
[3] Cohn. M. \& Kottkamp.B. (1993). Teachers: the Missing Voice in Education. Albany: State University of New York press.

[4] Cruickshank.DR. \& Applegate.JH. (1981). Reflective teaching as a strategy for teacher growth, Educational Learnership, vol.38, 4-6.

[5] Dewey.J. (1933). How we think, $5^{\text {th }}$ edn. Lexington: D.C. Heath and Company.

[6] Elliot.J. (1991). Action research for educational change. Buckingham: Open University Press.

[7] Gage.N \& Berliner.D. (1991). Educational Psychology, $5^{\text {th }}$ edn. Boston: Houghton, Mifflin.

[8] Needly.AM. (1986). Planning and problem solving in teacher education, Journal of teacher education, vol. 32, no. 3, 29-33.

[9] Osterman.K. \& Kottkamp.R (2004). Reflective Practice for Educators: Professional Development to Improve Student Learning, $2^{\text {nd }}$ edn. Thousand Oaks: Corwin Press.

[10] Pennington.M. (1991).Work satisfaction in teaching English as a second language. Department of English Research Report No. 5, 11-14.

[11] Pollard.A. (2005). Reflective teaching, $2^{\text {nd }}$ edn. London, Continuum.

[12] Richard, JC. \& Lockhart, C. (1996). Teacher development through peer observation. TESOL Journal, vol. 1, no. 2, 7-10.

[13] Saunders.W. (1992). The constructivist perspective: implications and teaching strategies for science. School Science and Mathematics, vol. 92, no.3, 136-141.

[14] Schon.D.A.(1988). Coaching reflective teaching in Crimmett, P \& Erickson, G, Reflection in teacher education, New York, NY: teacher college press, 12, 19-30.

[15] Shavelson.R. (1973). What is the basic teaching skill. Journal of Teacher education, vol. 24, no. 2, 44-51.

[16] Simpson. D., Jackson. M. \& Aycook. J. (2005). John Dewey and the Art of Teaching: Toward Reflective and Imaginative Practice, Thousand Oaks: Sage.

[17] Steffe.L. (1990). Overview of the action group A1: Early childhood years, In Steffe, L \& Wood, T, Transforming early childhood mathematics education: An international perspective. Hillsdale: Lawrence Erlbaum, 152.

[18] Vygotsky. LS. (1978). Mind in Society: The development of higher psychological processes. Cambridge: Harvard University Press.

[19] Wheatley.GH. (1991). Constructivist perspectives on science and mathematics learning, Science Education, vol. 75, no. 1, 9-21.

[20] Wilson.B. \& Cole.P. (2000). A review of cognitive teaching models, Educational Technology Research and Development Journal, vol.39, no.4, 47-54.

[21] Zeichner.KM. (1981). Reflective teaching and field-based experience in teacher education, Interchange, vol.12, no. 1,22-24

[22] Xin Yule. (2006). Teaching of Reflection, Sichuan: Sichuan Education Press.

[23] Xiong Chuanwu. (1999). Reflective Teaching, Shanghai: East China Normal University Press,3-223

[24] Weining. (2005). A Study of Teachers' Reflection, Educational Science Study, 9: 23-25

Junqiu Wu was born in Shandong, China in 1983. She got the MA of Arts at Shanghai Institute of Foreign Trade, China in 2010. She was currently a lecturer in Foreign Language Department in Huaiyin Institute of Technology, Jiangsu, China. Her research interest is business English.

Yongpeng Wu was born in Shandong, China in 1991. He is studying in South China Normal University. He is major in Training in College of Physical Science. 